\title{
Smart Car Parking System
}

\author{
Sunil Dhakne ${ }^{1}$, Umakant Kengar ${ }^{2}$, Prof. R.S. Suryawanshi ${ }^{3}$, Abhishek Bhagat ${ }^{4}$, Avishkar Chavan ${ }^{5}$ \\ Student, Computer Dept, TCOER, Pune, India ${ }^{1,2,4,5}$ \\ Professor, Computer Dept, TCOER, Pune, India ${ }^{3}$
}

\begin{abstract}
Absence of space accessibility has dependably been an issue in urban territories and significant urban communities and to add to it there are autos stopped unfeelingly in the city that further point of confinement the space Car stopping is real sympathy toward metro urban areas. Uniquely, enormous urban areas require administration of space for auto stopping. Stopping of auto is exorbitant process. It expends time and cash of individuals. Keeping in mind the end goal to handle the issue of stopping in occupied spots different sorts of vehicle stopping frameworks are utilized overall to be specific Multi-level Automated Car Parking. The present venture work is meant to build up a diminished working model of an auto stopping framework for stopping. This paper audits diverse Intelligent Parking Services utilized for stopping direction, stopping office administration and gives an understanding into the financial investigation of such undertakings.
\end{abstract}

Keywords: Dynamic pricing, dynamic resource allocation,mixed integer linear programming (MILP), reservation, smart carparking.

\section{INTRODUCTION}

The mechanical development of the world is reflected by the expansion in the quantity of cars in the city all through the world [1], which has created a considerable measure of stopping related issues. The look for the parking spot is a period devouring procedure which influences the financial exercises' proficiency, as well as the social cooperations and cost [2]. Organize organizations can't give upgraded data of the stopping offices on the web as the stopping offices don't coordinate with the organizations. Certain enormous autos are not ready to fit into the regularly accessible parking spots.

Thus there is a requirement for a framework; which can contemplate all important data, for finding the stopping opportunity. Human mistake can bring about different trouble in fundamental region. Growing such framework can maintain a strategic distance from mishaps, checking parking area, direction to stopping office. The Intelligent Parking administration, an a portion of Intelligent Transportation System (ITS), [1,5]gives ascend to various stopping offices on the premise of new capacities they give. This administration not just deals with the inside operations of the stopping office, however it is additionally intended to work with various perspectives identified with the stopping office.

\section{LITERATURE SURVEY}

1] Faheem1*, S.A. Mahmud1 , G.M. Khan1 , M. Rahman1 and H. Zafar2," A Survey of Intelligent Car Parking System", 4 Vol. 11, October 2013

In this paper, various systems that provide intelligent parking services are discussed. These systems can counter the parking problems that arise due to the unavailability of a reliable, efficient and modern Parking system.
2] Chandni Patel\#1, Monalisa Swami \#2, PriyaSaxena \#3, Sejal Shah\#4," Rotary Automated Car Parking System", Volume 4, Issue 2, March 2015

The RACPS has been designed and all the composite parts in it have been manufactured and assembled. Analysis of the model has to be done while developing a life size model. The mechanical model has been designed and the software as well as the control circuit has been implemented successfully. It demonstrates the working of the planned rotary parking system. The size and number of trolleys can be customized according to the needs and capacity of the organization or garage space availability

3] M. M. Rashid, A. Musa, M. Ataur Rahman, and N. Farahana, A. Farhana," Automatic Parking Management System and Parking Fee Collection Based on Number Plate Recognition”, No. 2, April 2012

In this paper the development of an automatic parking system with license plate recognition, parking lots status and guidance parking system and electronic billing system is successfully implemented. The performance of the developed of algorithms for License Plate Localization and License Plate.

4] Ramneet Kaur and Balwinder Singh," DESIGN AND IMPLEMENTATION OF CAR PARKING SYSTEM ON FPGA”, Vol.4, No.3, June 2013

Parking system is implemented using Finite State Machine modelling. The system has two main modules i.e. identification module and slot checking module. Identification module identifies the visitor. Slot checking module checks the slot status. These modules are modelled in HDL and implemented on FPGA. 


\section{OUR APPROACH}

To utilize space available for car parking, we are proposing a efficient car parking system. We are using Dijkstra's algorithm for finding shortest path. This is effective method to avoid traffic congestion. Developing this application can increase in parking revenue. Many parking resources are available.

We can calculatedly utilize this resources. The parking information system along with the parking space negotiation system laid the foundation for the intelligent parking service and it can counter all the traffic related issues working hand in hand with each other. We are combining hardware and software parts to execute this plan.

\section{PROPOSED SYSTEM}

\section{System introduction}

We are proposing smart car parking system. Here, hardware and software parts are combine to execute this application. We are using two sensors. First sensor is installed at entry door of parking system.

Another sensor is installed at exit point. Dynamic[4] searching is available for finding nearest location available for searching. Vacant place are available for new car parking.

\section{System module}

\section{- Detecting}

Vehicle is detected by sensor when it come in range of area. The method discussed in [4] gives a car the capability to independently drive on different types of roads. It also envisions movements like reverse, parallel parking and three point turns

- Wireless sensor network

We are providing sensor to detect enrty and exit of system. They arrange themselves for making an ad hoc network through the wireless communication module present on nodes.

\section{- Supplying information}

All information regarding to vehicle is sent to system. Action are taken according to requirement. This information is stored in database.

\section{System features}

- System will utilize available space for parking

- This will help to avoid traffic congestion

- It will increase in park resource utilization

- Also, it will increase in parking revenue,

\section{DIAGRAM}

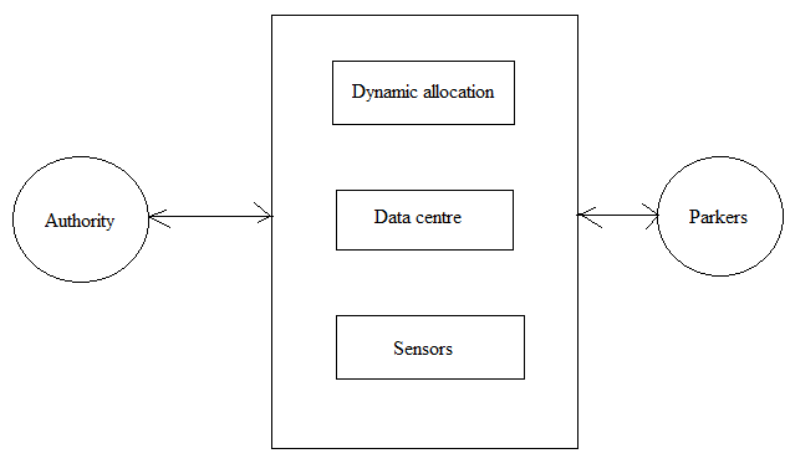

Block diagram of smart car parking

\section{ALGORITHM TO BE USED}

1] Dijkstra's algorithm

This algorithm has been used in GPS navigating systems.

For a given source vertex (node) in the graph, the algorithm can be used to find shortest path from a single starting vertex to a single destination vertex.

For example, if the vertices of the graph represent cities and edge path costs represent driving distances between pairs of cities connected by a direct road, Dijkstra's algorithm can be used to find the shortest route between one city (a) and destination city (b).

- This algorithm is widely used in routing protocol systems

- It is also called the single-source shortest path problem, in which the shortest paths from a single source (vertex) to all other vertices has to be found.

In the next example; for a given source vertex (node) in the graph, the algorithm finds the path with the shortest path between that vertex and every other vertex. A Java applet has been used to show the process step by step.

\section{MATHEMATICAL MODEL}

Let_S' be the $\mid$ system in the final set

$\mathrm{S}=\{\ldots \ldots \ldots \ldots\}$

Identify the inputs as I

$\mathrm{S}=\{\mathrm{C}\}$

$\mathrm{C}=\{\mathrm{c} 1, \mathrm{c} 2, \mathrm{c} 3, \mathrm{c} 4 \ldots \mid \mathrm{C}$ is set of cars $\}$

Identify the outputs as $\mathrm{O}$

$\mathrm{S}=\{\mathrm{P}\}$

$\mathrm{P}=\{\mathrm{P} 1, \mathrm{P} 2, \mathrm{P} 3, \ldots \ldots \ldots . \mathrm{P}$ is allotted place for car $\}$

Identify the functions as $\mathrm{F}^{6}$

$\mathrm{S}=\{\ldots$

$\mathrm{F}=\{\mathrm{F} 1(), \mathrm{F} 2(), \mathrm{F} 3(), \mathrm{F} 4(), \mathrm{F} 5(), \mathrm{F} 6()\}$

$\mathrm{F} 1(\mathrm{~V})=$ User will search for nearest parking location.

$\mathrm{F} 2(\mathrm{~V})=$ User will asked for vacant place

$\mathrm{F} 3(\mathrm{~V})=$ Shortest path is found

$\mathrm{F} 4(\mathrm{~V})=$ Car is parked

F5 (V) = Payment is done

F6 (V) =System will be updated 


\section{CONCLUSION}

The new ideas presented in this paper are the mix of continuous reservations with share-time reservations, powerfully performing framework choices (reservation time imperatives and evaluating) as per constant usage data, and offering the drivers the decision of picking different goals and reservation sort. We likewise have proposed estimating strategies for both static and element reservations that augment the benefit from stopping.

\section{FUTURE SCOPE}

1. The parking availability information system and parking reservation system should provide advanced navigation services.

2. The mobile electric commerce system and a continuously working gate system should collect the toll charges electrically.

3. An automated navigation system should assist in safe driving.

4. An in-facility navigation system should provide the best possible traffic management.

5. Provision of effective security for the safety of cars.

6. Provision of strong functions for facilitating administrators and managers in management of the parking facility.

\section{REFERENCES}

[1] L. Wenghong, X.Fanghua, L. Fasheng, "Design of Inner Intelligent Car Parking System", International Conference on Information Management, Innovation Management and Industrial Engineering 2008.

[2] C.C. Li, S.Y. Chou, S.W. Lin, "An agent-based platform for drivers and car parks negotiation", 2004 IEEE International Conference on Networking, Sensing and Control, pp. 1038- 1043, 2004.

[3] R. E. Knack, "Pay as you park," Planning, vol. 71, no. 5, pp. 4-8, May 2005.

[4] National Travel Survey England, Department for Transport,

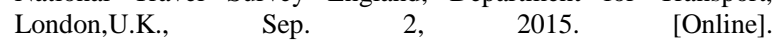
Available:https://www.gov.uk/government/uploads/system/uploads/ attachment_data/file/457752/nts2014-01.pdf.

[5] D. C. Shoup, "Cruising for parking," Transp. Policy, vol. 13, no. 6,pp. 479-486, Nov. 2006.

A. le Fauconnier and E. Gantelet, "The time looking for a parking space:Strategies, associated nuisances and stakes of parking management infrance," in Proc. ETC, Sep. 2006, pp. 1-7.

[6] IBM Global Parking Survey: Drivers Share Worldwide Parking Woes,IBM, Armonk, NY, USA, Sep. 28, 2011. [Online]. Available: https://www-03.ibm.com/press/us/en/pressrelease/35515.wss.

[7] D. C. Shoup, "The high cost of free parking," J. Plann. Educ. Res., vol. 17,no. 1, pp. 3-20, Fall 1997.

[8] K. Mouskos, J. Tvantzis, D. Bernstein, and A. Sansil, "Mathematicalformulation of a deterministic Parking Reservation System (PRS) withfixed costs," in Proc. 10th MELECON, 2000, vol. 2, pp. 648-651. 